\title{
Work Experiences, Accommodations, and Information in the Context of Fibromyalgia: A Literature Review and Conceptual Synthesis
}

Annie T. Chen, University of Washington, USA

Holly Carpenter, University of Illinois at Urbana-Champaign, USA

Mary Grace Flaherty, University of North Carolina at Chapel Hill, USA

\begin{abstract}
This paper explores the challenges that individuals with fibromyalgia may experience in navigating the workplace. Fibromyalgia is a syndrome characterized by chronic widespread pain, stiffness, sleep disruption, and other symptoms, without a well-defined underlying disease. At work, patients can struggle with various problems, including fluctuating symptoms, exhaustion, skepticism, questions about whether to disclose, and finding ways to adjust work situations. Individuals often lack information concerning how to manage their health, as well as different aspects of their lives, including work.

Work accommodations such as extended health benefits, modified schedules, and work-at-home arrangements could help. However, individuals may need to learn how to advocate for themselves, which can include finding information on legal rights and accommodation options. Differences in information awareness and seeking skills can lead to inequities in the management of chronic health conditions in the workplace.

We explore extant literature in three parts. First, we review research on the experience of work among individuals with fibromyalgia, and to a lesser extent, other conditions and disabilities. Then, we consider work accommodations, and third, we conclude with a conceptual synthesis.

In our analysis, we first identify a need for clearer conceptualization of the role of information to facilitate workplace self-advocacy. Then, we identify gaps in the literature concerning information and information behavior related to work accommodations. Last, we emphasize the need for involvement of stakeholders over time. This paper may be of interest to researchers, health care providers, library and information science professionals, and health policy researchers striving to achieve health equity.
\end{abstract}

Keywords: chronic illness; fibromyalgia; information behavior; information provision; work accommodations

Publication Type: review article

The International Journal of Information, Diversity, \& Inclusion, 3(3), 2019

ISSN 2574-3430, jps.library.utoronto.ca/index.php/ijidi/index

DOI: $10.33137 /$ ijidi.v3i3.32964 


\section{Introduction}

$\mathrm{P}$ eople with chronic conditions face challenges in many facets of their lives, and the workplace is no exception. Many symptoms and health-related needs can affect work. These include: fatigue, pain, weakness, nausea, issues with concentration, and managing a precise medication schedule, meal schedule, or diet. To remain in the workforce, people with chronic illnesses must learn self-advocacy strategies so they can effectively navigate the process of determining what, when, to whom and how to disclose their illness and needs, and to request and negotiate reasonable accommodations. Information can play a critical role in the development of these self-advocacy strategies as personal, interpersonal, and structural differences may contribute to the outcomes of their interactions. These tasks can be particularly difficult for those with "invisible conditions," in which individuals often deal with symptoms that are unobservable to others.

In this article, we explore challenges that one group of individuals with invisible symptomsfibromyalgia patients-may experience in navigating the workplace. Fibromyalgia is a syndrome characterized by chronic widespread pain, joint stiffness, sleep disruption, and other systemic symptoms, including mood disorders, fatigue, and cognitive dysfunction, without a well-defined underlying disease (Bellato et al., 2012; Wolfe, Brähler, Hinz, \& Häuser, 2013). The lack of clear answers and solutions for their health issues is often accompanied by extensive information seeking (Chen, 2016). In relation to work, people with fibromyalgia can struggle with confusion, fluctuating symptoms, and exhaustion (Sallinen, Kukkurainen, Peltokallio, \& Mikkelsson, 2010). Patients with fibromyalgia tend to experience greater loss in work productivity and greater health resource utilization than those without fibromyalgia (Lee et al., 2016; Walitt, Nahin, Katz, Bergman, \& Wolfe, 2015).

People with fibromyalgia may also experience various challenges at work, including facing skepticism from coworkers (Oldfield, MacEachen, Kirsh, \& MacNeill, 2017), deciding whether to disclose their symptoms (Oldfield et al., 2017), and finding ways to adjust their work situations (Liedberg \& Henriksson, 2002). Over time, individuals with fibromyalgia often transition from full-time to part-time work, and/or from more to less stressful types of work (Mannerkorpi \& Gard, 2012). Extant literature has reported that those who remain at work learn or develop ways of making it possible to continue working (Chen, 2015). However, questions remain about the role that information plays in helping people to develop these strategies. There can be great diversity in the experiences that people with fibromyalgia have in their effort to develop and maintain an acceptable work situation, as there are many individual, social, work, and societallevel factors that can shape individuals' work experiences.

Individuals with chronic pain-related conditions may benefit from work accommodations. Examples of accommodations include extended health benefits, short term leave, flexible hours or flextime, modified schedules, change in job duties, reassignment to another position, special equipment or adaptations, and work-at-home arrangements (Al Dhanhani, Gignac, Beaton, Su, \& Fortin, 2015; Gignac, Cao, \& McAlpine, 2015; Leslie, Kinyanjui, Bishop, Rumrill, \& Roessler, 2015).

There is limited academic literature on work accommodations that may be useful to people with fibromyalgia and their experiences requesting these accommodations. However, there is literature pertaining to other conditions in which individuals experience chronic pain, such as multiple sclerosis and arthritis. Moreover, there is substantive literature relating to disabilities

The International Journal of Information, Diversity, \& Inclusion, 3(3), 2019

ISSN 2574-3430, jps.library.utoronto.ca/index.php/ijidi/index

DOI: $10.33137 /$ ijidi.v3i3.32964 
and invisible disabilities, for example, concerning the need for organizational support. Thus, although in this article we focus on the experiences of work in the context of fibromyalgia, we also draw upon literature pertaining to pain-related conditions and disabilities, as well as to invisible disabilities more broadly, which may be related to the challenges experienced by individuals with fibromyalgia in work contexts.

In this article, we examine fibromyalgia patients' experiences of work and their ability to navigate the workplace in three parts. First, we consider issues that people with fibromyalgia and/or other chronic pain conditions and disabilities face in work contexts. Then, we review the literature to understand the work accommodations that might be provided. In our conceptual synthesis, we articulate gaps, with a particular focus on information. We note the lack of conceptual models that illustrate the role of information in workplace self-advocacy; a lack of knowledge about the information resources available to, and information behaviors of, individuals who need work accommodations; and the need for mutual consideration and effort from all stakeholders over time. This article is thus organized into the following main sections: the experience of work, work accommodations, and conceptual synthesis.

\section{The Experience of Work}

We first review extant literature on the work experiences of people with fibromyalgia. To a lesser extent, we also consider literature on work experience relating to individuals with other chronic conditions and disabilities, which often report similar experiences. We focus on four primary themes: the struggle to stay at work; strategies and factors to success; stigma, identity, and disclosure; and reflecting upon work experiences and the path forward.

\section{The Struggle to Stay at Work}

Individuals with chronic pain-related conditions often experience work transitions over the course of their illness. Previous research has reported a notable decrease in employment following diagnosis of fibromyalgia (Burckhardt, Liedberg, Henriksson, \& Kendall, 2005; Guymer, Littlejohn, Brand, \& Kwiatek, 2016). There are often transitions from a higher to a lower occupation level and from full-time to part-time work (Söderberg \& Lundman, 2001). Similarly, in one study of individuals with inflammatory arthritis and osteoarthritis, work transitions such as productivity losses (absenteeism, job disruptions), work changes (reduced hours, changing jobs), and leaving employment were reported in $76.5 \%$ of participants (Gignac, Cao, Lacaille, Anis, \& Badley, 2008).

In the case of fibromyalgia, the symptoms that most commonly interfere with work ability are pain, fatigue, muscle weakness, and memory and concentration difficulties (White, Speechley, Harth, \& Ostbye, 1999). Individuals with fibromyalgia and other types of chronic pain may also struggle with the unpredictable nature of flare-ups (Toye et al., 2016), acceptance of their condition (Varekamp \& van Dijk, 2010), and balancing home and work life (Varekamp \& van Dijk, 2010).

Though an extensive discussion is beyond the scope of this work, gender can also play a role in the work experiences of those with fibromyalgia. As previous literature has observed, gender segregation occurs within occupations, with women more frequently performing repetitive work tasks that may cause physical strain; women also often have greater responsibilities for unpaid work at home, which can impede their ability to recover after work (Barker, 2005; Henriksson,

The International Journal of Information, Diversity, \& Inclusion, 3(3), 2019

ISSN 2574-3430, jps. library.utoronto.ca/index.php/ijidi/index

DOI: $10.33137 /$ ijidi.v3i3.32964 
Liedberg, \& Gerdle, 2005)." Also, it has been argued that perceptions of fibromyalgia as a disease with an ambiguous definition that primarily affects women means that it is not prioritized as a health concern (Briones-Vozmediano, 2016).

For those with chronic conditions, there can be many barriers to staying at work. These can include issues relating to work site access (e.g., stairs) and conditions (e.g., temperature, schedule), job functions (physical, cognitive, task-related, and social), and company policies (Allaire, Wei Li, \& LaValley, 2003; Mancuso, Paget, \& Charlson, 2000). Individuals with musculoskeletal diseases may also have trouble interacting with and being understood by colleagues and supervisors, particularly because the symptoms they experience, such as fatigue and pain, are not visible and their severity can be underestimated (Crooks, 2007b). In addition, there is often a lack of organizational support to facilitate a return to work (Toye et al., 2016). If an employee is considering whether to return to work after a period of not working, they may be concerned about doing so due to the uncertainty of being able to access benefits, as well as considerations of fit between their capabilities and the job. Though lack of social support from supervisors is often reported, there are also occasions in which individuals report having a supervisor who was understanding about the need for flexibility. This appeared to strengthen individuals' confidence in their abilities to continue working (Mannerkorpi \& Gard, 2012).

This section has shown that individuals with fibromyalgia and other chronic conditions may face many challenges in their struggle to stay at work. However, despite these challenges, there can be many reasons why people may want to continue working. At the outset, work is often valued as part of a person's identity (Palstam, Gard, \& Mannerkorpi, 2013), and the loss of the ability to work can be devastating (Juuso, Skär, Sundin, \& Söderberg, 2016). Working can offer individuals a sense of purpose and the opportunity to feel that they are contributing to society and helping others (de Vries, Brouwer, Groothoff, Geertzen, \& Reneman, 2011; Liedberg \& Henriksson, 2002; Meade, Rumrill, Krause, Reed, \& Aust, 2016). In addition, individuals often have a financial need for the income (de Vries et al., 2011; Meade et al., 2016; Whei-Mei, LeeIng, Hsiu-Chin, \& Pin-Ru, 2018). Work can also be seen as energizing, therapy in the form of distraction from pain, and providing structure, social contacts, and self-respect (de Vries et al., 2011). Overall, previous research has reported that women with fibromyalgia who were working were more satisfied than those who did not work (as cited in Henriksson et al., 2005).

\section{Strategies and Factors to Success}

There are both societal and individual level factors that contribute to the possibility of individuals remaining at work (Liedberg \& Henriksson, 2002). At the societal level, there are values and norms. Individuals tend to feel that by working, one is contributing to society. Work also provides meaning, fulfillment, and an organized time structure. Structural factors in society, such as work restructuring, finances, and commuting, may complicate an individual's work situation. Commuting via public transportation can be difficult for reasons such as the inability to walk even short distances. At the individual level, factors affecting individuals' work situations include their working conditions, the physicality of the work, psychosocial environment, other commitments, unpaid work (e.g. home maintenance, raising children, and taking care of elderly relatives), and social relations.

For fibromyalgia patients, limited physical capacity, increased stress, and an increased need of rest are the major health problems that prevent patients from working (Mannerkorpi \& Gard, 2012). Successful strategies include: taking a slower pace, splitting activities, prioritizing,

The International Journal of Information, Diversity, \& Inclusion, 3(3), 2019

ISSN 2574-3430, jps.library.utoronto.ca/index.php/ijidi/index

DOI: $10.33137 /$ ijidi.v3i3.32964 
planning, resting, heat, exercise, keeping fit, perceiving signals from the body and heeding those signals, telling oneself that the pain is not dangerous, positive thoughts, enjoying life as much as possible, maintaining a positive view of life, and an unwillingness to give in (Löfgren, Ekholm, \& Öhman, 2006). Personal characteristics that contribute to success include: perseverance, positive outlook, communicative abilities, courage, coping with pain (e.g. pain medication, ignoring pain, remaining active, avoiding provocative movements, pain acceptance), use of healthcare services, pain beliefs, and adjustment latitude (de Vries et al., 2011). Adjustment latitude includes the ability to increase capacity by training and remaining active, lowering load by accepting help and other mechanisms, making modifications at work and in working conditions, and receiving support. Rejection of the disability identity and 'not giving in' have also been seen as important factors contributing to success (Oldfield, MacEachen, MacNeill, \& Kirsh, 2018). In addition, people may make strategic decisions, including switching career paths entirely, once they realize that they need to make adjustments to their lives to improve their health (Chen, 2016; Palstam et al., 2013). Lastly, learning/being knowledgeable, creative solutions, managing stressful situations and ergonomics can also be important (Löfgren et al., 2006).

In terms of the effects of fibromyalgia on family life, research literature often reports negative impacts, including lack of understanding from family, strain due to having to rely more on family members for tasks, and the dual strain of work and home responsibilities (e.g., Ashe, Furness, Taylor, Haywood-Small, \& Lawson, 2017; Collado et al., 2014; Söderberg, Strand, Haapala, \& Lundman, 2003), but there are also instances in which individuals receive support from family (Cooper \& Gilbert, 2017). There is significantly less research concerning supporting roles that family may play in enabling fibromyalgia patients to continue working, though it has been reported that family members have provided support by taking over household chores, providing moral support, and encouraging individuals to rest when needed (Palstam et al., 2013).

There are also work-related characteristics that can facilitate a person's success at continuing to work productively. These include aspects of the work itself, including recovery opportunities, work balance (suitable pace and workload), and aspects of the work environment, such as understanding and help from colleagues and support from management (Bossema et al., 2012; Palstam et al., 2013). Factors affecting the successful provisioning of work accommodations will be discussed later in the article.

Lastly, government organizations may play a role in assisting individuals to remain at work. For example, previous interview research has reported that the Swedish Social Insurance Agency (SIA) can play an important role in providing financial aid to enable individuals to reduce their work hours and provide time for recovery in the long-term (Palstam et al., 2013). Other research, however, has found that although there are times when interactions with the SIA are coherent, leading to facilitating recovery and a return to work, there are also times when such interactions are fragmented and impede the process of returning to work (Hubertsson, Petersson, Arvidsson, \& Thorstensson, 2011).

\section{Stigma, Identity, and Disclosure}

One major challenge that individuals with fibromyalgia and other disabilities face is the question of whether to disclose one's illness in the workplace. In work environments, individuals with fibromyalgia and/or other conditions that lead to disability can struggle with skepticism, being labeled negatively, being viewed differently by supervisors and/or co-workers, and

The International Journal of Information, Diversity, \& Inclusion, 3(3), 2019

ISSN 2574-3430, jps. library.utoronto.ca/index.php/ijidi/index

DOI: $10.33137 /$ ijidi.v3i3.32964 
discrimination (Gold, Oire, Fabian, \& Wewiorski, 2012; Oldfield, MacEachen, Kirsh, \& MacNeill, 2016; Oldfield et al., 2017; Schrader, Malzer, \& Bruyère, 2014; Toye et al., 2016). Individuals often feel that they need to "prove" their disability to others and affirm oneself as a good worker (Santuzzi, Waltz, Finkelstein, \& Rupp, 2014; Toye et al., 2016).

Often, people disclose at the time when the need to obtain accommodations arises. But there are barriers to disclosure. Disclosure may be the first step to discrimination. People struggle with the question of whether to "pass" or "reveal" an invisible identity in the workplace (Clair, Beatty, \& Maclean, 2005), and "impromptu disclosure dances" occur when people with fibromyalgia need to improvise an explanation on the spot to explain why they cannot do a given task (Oldfield et al., 2016).

The question of when to disclose can be difficult for many. Salient factors that can affect the decision include the degree to which accommodations are needed and the visibility of the disability. Individuals with a visible disability are more likely to disclose their disability earlier in the employment process (Jans, Kaye, \& Jones, 2012). Individuals with a less apparent disability are more likely than those who have a more apparent disability to be concerned about being fired/not hired, loss of health care benefits, limited opportunities for promotion, being treated or viewed differently, and keeping the disability private (Schrader et al., 2014). Individuals may also disclose their illness to different extents, e.g. partial disclosure to a line manager about the presence of their illness, as opposed to full disclosure of how the illness affects them at work (Munir, Leka, \& Griffiths, 2005). In order to disclose, people also have to accept that the challenges or symptoms they experience are a legitimate disability (Santuzzi et al., 2014). Because the difficulties that individuals with fibromyalgia experience are often not visible, the disclosure decisions they make are perhaps more similar to those with disabilities that are not as visible.

Important factors in disclosure include the need for an accommodation and having a supportive supervisor relationship (Munir et al., 2005; Schrader et al., 2014). However, other factors, such as knowing that an employer has made an effort to create a disability-friendly workplace, knowing that an employer was actively recruiting people with disabilities, knowing of employees who had disclosed and were successful, inclusion of disability in the diversity statement, knowing that disclosure could potentially pave the way to new opportunities for promotion or training, seeing a message of disability inclusiveness on the company's materials, seeing employees with disabilities at recruitment events, and employers having a disability-focused employee resource group (ERG), can also play a role in an individual's willingness to disclose and seek accommodations (Purc-Stephenson, Dostie, \& Smith, 2018; Schrader et al., 2014).

\section{Reflecting Upon Work Experiences and the Path Forward}

Individuals with fibromyalgia and other chronic conditions often experience difficulty at work. These difficulties arise due to a complex interplay involving health factors, psychosocial factors, life situations, organizational support and workplace climate. Despite these challenges, individuals often desire to continue working due to benefits experienced from doing so, such as income, a sense of purpose and meaning, distraction from pain, and a sense of routine and structure. Due to the challenges that they face in the workplace, individuals may struggle with questions about their identity, and whether and how to disclose their illness to others. The act of disclosure is often one that arises out of need. Workplace climate and perceived support of colleagues and supervisors play an important role in disclosure.

The International Journal of Information, Diversity, \& Inclusion, 3(3), 2019

ISSN 2574-3430, jps.library.utoronto.ca/index.php/ijidi/index

DOI: $10.33137 /$ ijidi.v3i3.32964 
Though there is substantive literature on the experience of work for those with fibromyalgia, there are questions that remain unanswered. For example, though the literature illustrates a trend towards working part-time or not at all after symptom onset and diagnosis of fibromyalgia, one might wonder if there are potential ways to enable individuals to keep working. In addition, the literature that we have considered does not help us to understand whether people with fibromyalgia have the information and knowledge that they need to improve their work situations. We explore these questions further in subsequent sections.

\section{Work Accommodations}

Previous research has shown that the provision of work accommodations is associated with greater satisfaction and is a process, as opposed to a one-time event (MacDonald-Wilson, Fabian, \& Dong, 2008). In this section, we consider the process of requesting and negotiating work accommodations and factors affecting the provision of accommodations. There is less research on work accommodations that is specific to the context of fibromyalgia, so we draw upon literature concerning workplace accommodations and interventions more broadly, and more specifically in the context of the U.S.

\section{Requesting and Negotiating Work Accommodations}

One important part of receiving accommodations involves accommodation requests. In the U.S., the Americans with Disabilities Act (ADA) protects the rights of workers with disabilities, requiring employers to provide accommodations to employees with disabilities (Americans with Disabilities Act of 1990, 1990; Gold et al., 2012). However, the responsibility to request accommodations still rests with the employee. To request accommodations, an employee should develop a list of the accommodations that they need, illustrate how each would increase their productivity, and consider how an employer or supervisor might respond (Gold et al., 2012; Rumrill et al., 2016). Important considerations for the employer might be whether the accommodation would be cost-effective and how it would alter the nature of the business.

Requesting accommodations can be challenging for individuals, particularly since they may be struggling to come to terms with their condition and what they can do about it. Many people with invisible disabilities wait until after they are hired to disclose (Santuzzi et al., 2014). Previous literature on use of work accommodations for multiple conditions has shown that the level of severity of symptoms is associated with usage of work accommodations (Allaire et al., 2003; Leslie et al., 2015). In addition, people may wait too long to make plans for symptom management and to ask for accommodations, until such planning is too late to be effective (Sallinen et al., 2010; Simmons, Tribe, \& McDonald, 2010). Providing information to employees about how to ask for accommodations and what types of accommodations might be helpful may encourage them to disclose earlier.

\section{Factors Affecting the Provision of Work Accommodations}

In this section, we consider key factors that can affect the effectiveness of accommodations and workplace interventions. Difficulties can arise due to the introduction of accommodations, resulting in disruptions and/or ill effects to the individual or organization, or the social environment of the workplace (Santuzzi et al., 2014). For example, if a worker with an invisible disability chooses not to make their condition known to their colleagues, the ADA prohibits the employer from making the disability known in the provision of accommodations. This can result

The International Journal of Information, Diversity, \& Inclusion, 3(3), 2019

ISSN 2574-3430, jps. library.utoronto.ca/index.php/ijidi/index

DOI: $10.33137 /$ ijidi.v3i3.32964 
in co-workers of an employee who is receiving an accommodation questioning why the individual is receiving it, which may create the potential for the perception of unfairness. Santuzzi et al. (2014) suggest that one way to mitigate this possibility is to identify accommodations that result in the least amount of disruption, such as allowing an individual to work remotely so that they can use assistive devices and take breaks as needed. Individuals may also be able to utilize accommodations that are available to all employees in a given setting, such as various kinds of leave, working remotely, and flexibility in hours worked. However, it is perhaps important to note that there are differences in the degree of flexibility that exists in different work environments, and these accommodations may not always be available.

Return-to-work processes can be complicated and involve many actors. Coordination of these actors can be difficult but invaluable in fostering successful work re-integration (Löfgren, Schult, Öhman, Julin, \& Ekholm, 2016). Services that can be extremely helpful include a multiprofessional team to provide coaching and work training, involving the employees affected in the shaping of the rehabilitation process, developing suitable accommodations for work tasks, matching employees' capacities and limitations, and the social support of colleagues (Glavare, Löfgren, \& Schult, 2012).

Previous research has shown that organizations and supervisors often instruct employees to accommodate a person who is returning to work without clearly explaining why or developing an organized plan for re-integration (Dunstan \& MacEachen, 2013). Doing so can leave co-workers feeling excluded from the planning and cause resentment. Previous research has argued that the perception of fairness is critical to reintegration, and that engaging co-workers in the planning, monitoring, and review of work reintegration will lead to more successful outcomes (Dunstan \& MacEachen, 2014).

Though there is a gap in the literature on workplace interventions for fibromyalgia, extant articles that synthesize research literature on workplace accommodations and workplace interventions for disabilities more broadly can help us to consider what might be helpful in the context of fibromyalgia. Key facilitators and barriers of employment include self-efficacy; selfadvocacy; support of the employer, co-workers, and community; training and counseling; and flexibility of work schedules and work organization; work autonomy; and strategies to promote workplace inclusion and integration (Nevala, Pehkonen, Koskela, Ruusuvuori, \& Anttila, 2015; Padkapayeva et al., 2017). However, the reviews have also noted that there was a low number of methodologically sound studies; that validated measures of work ability and functioning of disabled persons are needed; and that the barriers and facilitators identified in qualitative studies should be examined quantitatively.

Articles that synthesize research literature have also focused on vocational rehabilitation interventions (e.g. Palmer et al., 2012; Varekamp, Verbeek, \& van Dijk, 2006). Components of vocational rehabilitation interventions include work accommodations; return-to-work coordinators; ergonomic work site visits; education/training provided to supervisors, workers, or case managers; and work practice modification, such as advice for posture/stretching and pacing (Franche, Baril, Shaw, Nicholas, \& Loisel, 2005). A review of vocational rehabilitation interventions for chronic disease concluded that programs that involved training in requesting work accommodations and feelings of self-confidence or self-efficacy in dealing with workrelated problems appeared to be effective, but that additional research was needed (Varekamp et al., 2006).

The International Journal of Information, Diversity, \& Inclusion, 3(3), 2019

ISSN 2574-3430, jps. library.utoronto.ca/index.php/ijidi/index

DOI: $10.33137 /$ ijidi.v3i3.32964 
Taken together, the body of existing research suggests there is a need for additional research concerning facilitators such as self-efficacy and self-advocacy, and how to facilitate the development of these factors. Some of these may be related to an organization's response to disclosure of disability. For example, previous research involving individuals with multiple sclerosis elucidated two high-level themes: a focus on ability, which in turn led to enhanced perceptions of psychological safety and work efficacy; and a focus on disability, leading to diminished psychological safety and reduced perceptions of work efficacy (Kirk-Brown \& van Dijk, 2014). Disability-focused responses included being allocated menial work tasks, being overlooked for promotion, having work unfairly scrutinized, and not being included in discussions regarding the types of accommodations needed. For example, a worker might receive accommodations in terms of their work conditions, such as a change in their work location or hours of employment. Even if the act is well-intentioned, individuals might perceive it as a lack of their employer's confidence in their abilities. In contrast, ability-focused responses include affirmation of the value of the employee, and acknowledgment that employees would propose the adjustments that they desired.

Williams-Whitt et al. (2016) concluded that there was a disconnect between the scientific literature focused on improving coping and reducing discomfort for individual workers and employer-directed grey literature focused on making group-level changes to policy and procedures, thus leading to the concern that the results from research are not translated and implemented in organizations. This concern provides greater impetus for a holistic examination of the literature to identify the gaps and needs going forward.

\section{Reflecting Upon Work Accommodations and the Path Forward}

In this section, we summarized existing literature on work accommodations, including how individuals can go about requesting and negotiating work accommodations and factors affecting the provision of work accommodations. We suggested that ensuring individuals are aware of their right to ask for accommodations and how to do so could encourage them to disclose earlier. There are perhaps various ways an organization can facilitate this process. For example, they could ensure that individuals receive information about accommodations and how to request them during the onboarding process, and distribute this information periodically to all employees through e-newsletters, so that employees are aware of their rights and seek help if needed in a timely fashion. Additionally, organizations can create mechanisms through which individuals feel safe to communicate with co-workers and exchange information and advice about effective work management strategies, or encourage co-workers to create their own safe channels. Taking care to ensure that individuals' privacy is respected and confidentiality maintained are perhaps difficulties that may arise in the implementation of these mechanisms.

Various factors affect the provision of work accommodations, and complications can arise in provision that may disrupt the work environment and interaction between employees in organizations. This literature suggests that open communication in work environments in which employees can be involved in the planning for provisioning of work accommodations can facilitate successful work re-integration. Extant studies that synthesize research on vocational rehabilitation for individuals with disabilities suggests that interventions are effective, but also identified that there is a need for more research in this area.

Additionally, we observe that the bulk of this literature is focused on disabilities more generally, rather than fibromyalgia specifically. Though the work experiences of individuals with

The International Journal of Information, Diversity, \& Inclusion, 3(3), 2019

ISSN 2574-3430, jps. library.utoronto.ca/index.php/ijidi/index

DOI: $10.33137 /$ ijidi.v3i3.32964 
fibromyalgia may overlap substantially with individuals who experience other health-related challenges, each person's experience is unique due to a combination of factors. For example, an individual with fibromyalgia may choose to disclose to their co-workers, but co-workers may be skeptical due to the "invisible" nature of the person's condition. This experience may be different from that of a person with a more visible disability. In this sense, the literature on workplace accommodations in the context of invisible disabilities may be more conceptually applicable than research on disabilities more generally.

Individuals with fibromyalgia may also experience specific types of symptoms more acutely and therefore the challenges and management strategies that work for those with similar symptoms might be most pertinent to them. For example, an individual with fibromyalgia may experience joint pain that interferes with their ability to perform office tasks. They might benefit from learning about accommodation strategies used by individuals with other conditions, such as arthritis and multiple sclerosis, as they may experience similar problems.

\section{Conceptual Synthesis}

Based on the literature on the experience of work and work accommodations, we now consider the gaps that remain in our existing knowledge about how individuals with fibromyalgia manage their work lives, and directions for future research and provision of support services. We begin with a discussion of conceptual models and then proceed to explore the particular gap that we identify in these models: our understanding of information and information behavior relating to work in the context of chronic illness. We conclude by emphasizing the need for involvement from concerned stakeholders over time.

\section{Conceptual Models}

Individuals with chronic health conditions who seek work accommodations need supportive and informational services to navigate the process. The literature includes a number of models that address different aspects of the work experience and the process of seeking accommodations. We consider these models and the gaps in their capability to explain and pave a path toward effective working situations for individuals with chronic pain-related conditions.

At the outset, we mention two well-known models of disability. In the medical model of disability, a person's limitations are seen as the primary cause for disability, and a cure as the solution (Goering, 2015). This model places the focus of disability on the individual without considering the environment in which a person exists. The social model shifts the focus from the individual to the society that excludes them (Emens, 2017), making a critical distinction between impairment-"a state of the body that is non-standard"-and disability, conceptualized as a disadvantage or restriction that results from society not taking into account people who have impairments, which consequently results in exclusion of individuals from mainstream activities (Goering, 2015). An extensive discussion of models of disability is beyond the scope of this article, but interested readers might see for instance, Emens (2017), Goering (2015), and Oliver (1996).

Two models focus more concretely on the context of work and the accommodation-seeking process. Toye et al. (2016) employ meta-ethnography to synthesize qualitative studies that explored adults' experience of chronic non-malignant musculoskeletal pain. Based on their literature review, they develop a model that depicts the struggle to stay at work, in which work is central to the self. The healthcare system, benefits, agencies, and employers are key actors

The International Journal of Information, Diversity, \& Inclusion, 3(3), 2019

ISSN 2574-3430, jps. library.utoronto.ca/index.php/ijidi/index

DOI: $10.33137 /$ ijidi.v3i3.32964 
that do not always facilitate a return to work. The model also elucidates the main strategies that individuals use to stay at work: obtaining a flexible working situation, hiding pain, relying on colleagues, and obtaining sick leave.

The Job Sustainability Model, proposed for employees with arthritis, is organized in terms of three main aspects: personal factors, self-assessment and information gathering, and job sustainability strategies (Purc-Stephenson et al., 2018). In this model, an individual experiences a trigger event that causes them to engage in self-assessment and information gathering. Based on this experience, they weigh the perceived benefits and costs of taking action to maintain employment, and may utilize various work sustainability strategies, including making personal adjustments, using social support, exploring medical interventions, and seeking workplace accommodations.

Aside from models relating to work, there are also models of identity and disclosure that may be useful to researchers for conceptualizing work-related disclosure decisions. Santuzzi and Waltz (2016) argue that the disability identity is dynamic, complex, and contains multiple levels (legal, medical, and cultural; organizational; interpersonal; and intra-individual). Many of these levels can include interactions with entities outside the individual. Developing a disability identity that is in harmony with one's work identity and functional capacities can increase self-esteem and satisfaction with life, while failing to develop one can lead to psychological and physical health risks.

Santuzzi and Waltz' (2016) conceptualization of the disability identity calls attention to important points in our consideration of the role of identity in an individual's management of their work life. First, this model emphasizes the inter-relatedness of social and environmental factors on the work experience of individuals. Second, the model highlights that individuals must acknowledge and self-identify as a person with a disability in order to be able to utilize available services (Santuzzi \& Waltz, 2016). Last, Santuzzi and Waltz point out that disclosure forms typically ask workers to indicate disability status with a dichotomous choice (i.e. yes/no) or to opt out of answering, which may be inconsistent with the way individuals see themselves.

The Disclosure Decision-Making Model (DD-MM) seeks to explain the process through which individuals may disclose information (Greene, 2015). According to the model, individuals who are considering a disclosure assess five aspects of the information to be disclosed: stigma, preparation, prognosis, symptoms, and relevance to others. Then, the individual considers the receiver in terms of relational quality (e.g., intimacy and closeness) and anticipated response. If, after considering these factors, they are still inclined to share, the individual considers their own disclosure efficacy. The act of disclosure is thus predicated upon all of these processes, and if individuals choose to disclose, what they subsequently experience as a result of their disclosure (outcomes) then influences their subsequent decisions to disclose. Though this model has not been examined in relation to disclosures for work accommodations, the concepts included in the model, the potential to exit the model and not disclose, and the inclusion of the outcomes of previous disclosures as a factor in future decisions, all suggest that this model may be suitable to consider when examining how individuals with fibromyalgia consider whether or not to disclose their condition in the workplace.

Based on our review of the literature and relevant models, we summarize the areas in which there is existing work, and the conceptual gaps that are present. There is literature on the issues of identity and disclosure that individuals may grapple with and the barriers that people may

The International Journal of Information, Diversity, \& Inclusion, 3(3), 2019

ISSN 2574-3430, jps.library.utoronto.ca/index.php/ijidi/index

DOI: $10.33137 /$ ijidi.v3i3.32964 
encounter in requesting and receiving accommodations. Additionally, there is substantial literature on the experience of work, including the symptoms that people experience, the difficulties they may encounter in performing their jobs, and the issues they may encounter at work as a result of these difficulties.

The Job Sustainability Model (Purc-Stephenson et al., 2018) effectively depicts the process that an individual might experience as they deal with difficulties in their work lives. In addition, the model notes that information gathering facilitates the enactment of work sustainability strategies, thus highlighting the importance of information. However, the model does not illustrate how information exposure, source selection, and perception and comprehension of information sources influence an individual's behavior, and hence, how information can enable individuals with chronic conditions to make decisions that improve their work experiences.

There is considerably less research on the information available to those who may benefit from accommodations and the manner in which this information should be presented for optimal use. Previous research has reported that individuals with fibromyalgia often experience a period in which they are unaware of the need to seek help regarding their symptoms (Chen, 2016). Over time, their state of knowing their own body, managing their own health, and ability to express their needs to others (including health care providers) grows, often alongside a process of iterative information seeking. The process described by Chen (2016) might be considered akin to the path described in the Health Literacy Pathway Model, in which people incrementally develop skills that enable them to better manage their health (Edwards, Wood, Davies, \& Edwards, 2012), though the former emphasizes the initial lack of a clear conceptualization of the information and knowledge needed, which is acquired through a process of trial-and-error.

One important direction for future work involves the imperative to develop a clearer understanding of the role of information in the development of skills for self-advocacy at work. A clearer conceptualization of the process through which individuals learn self-advocacy skills could be used to inform the development of suitable points for information interventions, as well as to explain how individuals might differ in their abilities to advocate for themselves. For example, with regard to information behavior, we might consider how the information that individuals encounter varies by source, how this information might be interpreted, and how subsequent decision-making occurs. Integration of theories from information science and communications research, such as the Comprehensive Model of Information Seeking (Johnson \& Meischke, 1993), the Risk Information Seeking and Processing Model (Griffin et al., 2004; Yang, Aloe, \& Feeley, 2014), and the Disclosure Decision-Making Model (Greene, 2015) can potentially help us to understand how differences in individual characteristics might influence people's motivations and abilities to find, process, and use information about work accommodations. However, there is still a need to integrate the models and empirically examine the validity of an integrated model for conceptualizing how people, in practice, navigate their work lives.

\section{Facilitating Self-Advocacy through Information Provision}

In order to be able to advocate successfully for oneself in the workplace, individuals may need to have knowledge including: the nature of one's disability and the ways that it might impact one's work, one's rights to accommodations, the range of accommodations that could mitigate symptoms, and how to request and obtain accommodations. This knowledge is predicated upon both this information being available, and that individuals will encounter and be able to interpret this information. In this section, we consider issues that might arise with both of these premises.

The International Journal of Information, Diversity, \& Inclusion, 3(3), 2019

ISSN 2574-3430, jps.library.utoronto.ca/index.php/ijidi/index

DOI: $10.33137 /$ ijidi.v3i3.32964 
First, there is limited knowledge of information-seeking behavior among individuals with fibromyalgia, including the amount and type of information that they may want or seek about how to manage their condition in the workplace. In a survey of fibromyalgia patients' information preferences, Daraz, MacDermid, Wilkins, Gibson, and Shaw (2011) reported that almost $80 \%$ of respondents indicated that the impact of fibromyalgia on their work was a "very important" information need, but the survey did not investigate respondents' needs for information relating to work in greater detail. Similarly, there is limited literature concerning search behavior about fibromyalgia (Bragazzi et al., 2017) and discussions about fibromyalgia in online support groups (Barker, 2008; Chen, 2012), but this literature does not explore the types of questions that people may have with regard to fibromyalgia and work.

However, previous research involving multiple sclerosis patients has shown that only half of survey respondents knew their rights regarding job-related physical examinations, what to do if they encountered discrimination at work, understanding the risks and benefits of disclosing disability status to employers, and understanding the employment protections of Title $I$ in the ADA Amendments Act (ADAAA) (Rumrill et al., 2016). Other research has reported that individuals with disabilities rely on online sources, personal networks, and contacting employers directly when seeking job opportunities (Sundar et al., 2018). Use of community and government resources, such as vocational rehabilitation programs, was limited.

A variety of online information sources are available to individuals with fibromyalgia about work, including those provided by government agencies, advocacy groups, and disability law offices, as well as blogs and illness-related forums. We consider examples of information sources one might encounter if they were to seek information about work accommodations for fibromyalgia in the U.S., focusing on differences in the information encountered and the takeaways that one might have based on that information.

For example, performing a Google search with the keywords, "fibromyalgia work," one encounters a set of search results including consumer health resources, blogs, a web page by the National Fibromyalgia and Chronic Pain Association, and more. A web page by the Disability Benefits Center, an advertising service paid for by lawyers and advocates, addresses the question of whether an individual can keep working with fibromyalgia (Disability Benefits Center, 2019). This question appears to be an underlying theme of the search results.

The consumer health resources include WebMD's (2018) page, "Fibromyalgia: Work and Disability," which addresses eight questions, five of which relate to disability; and Verywell Health's page, "Can I keep working with fibromyalgia or ME/CFS [Myalgic Encephalomyelitis/Chronic Fatigue Syndrome]?," which tells the reader that it is possible to keep working, but that it might be necessary to make some changes (Dellwo, 2017). The VeryWell Health page explains that individuals have a legal right to accommodations, but does not go on to explain how one might go about requesting them. In contrast, the WebMD page notes that employees can talk to their managers about accommodations, but does not directly inform the reader that employees are legally entitled to accommodations or discuss potential consequences of requesting them. Without more discussion of what might happen, individuals may be reticent to act upon the information, and may also be less prepared for negative consequences, should they occur. Thus, these examples illustrate how information sources that individuals access when they begin searching about workplace issues might, on the one hand, steer individuals towards consideration of themselves as needing to leave the workforce and apply for disability benefits, and on the other, not impart the skills that they need to advocate for themselves in the

The International Journal of Information, Diversity, \& Inclusion, 3(3), 2019

ISSN 2574-3430, jps. library.utoronto.ca/index.php/ijidi/index

DOI: $10.33137 /$ ijidi.v3i3.32964 
workplace.

This phenomenon is consistent with the existing body of literature in two ways. First, previous research has reported that work structures often do not facilitate a return to work (Toye et al., 2016). Second, in an analysis of materials available for fibromyalgia through various self-help organizations, Oldfield (2014) observed that these resources tend to focus more on leaving paid employment and obtaining disability. Though some materials also address the possibility of employees remaining at work, they encourage individuals to manage their own symptoms and “make themselves fit for work" (Oldfield, 2014, p. 41). Additionally, employees' legal right to accommodations was not discussed.

There are information resources that provide more comprehensive coverage of how an individual might go about requesting accommodations. For example, the Job Accommodation Network provides guidance on workplace accommodations and disability employment issues (Job Accommodation Network, n.d.). The organization website includes information targeting individuals in many different roles (e.g., employee, employer, rehabilitation professional), a searchable online accommodation resource, and more. They have a resource entitled, "Employee's Practical Guide to Requesting and Negotiating Reasonable Accommodations under the Americans with Disabilities Act," which provides a list of questions and answers to concerns that individuals may have, e.g., 'What if I am not sure what accommodations I need?' This guide provides more detailed information than is offered in many other online information resources. However, the guide does not provide or direct individuals to information about other aspects of workplace climate that may deter individuals from requesting accommodations. Moreover, it is unclear whether individuals would naturally arrive at this website through a web search. The Job Accommodation Network does not appear on the first page of results of a web search with the keywords, "fibromyalgia work," though it does appear on the first page of web search with the keywords "fibromyalgia work accommodations." Thus, to find this resource easily, one might need to know to search using the keyword, "accommodations."

Let us consider another problem that individuals might encounter as they are searching for information. If individuals do not know whether they are qualified to ask for work accommodations, they might search to find the answer to this question. The Americans with Disabilities Act does not specifically name all of the conditions that are covered under the legislation (Americans with Disabilities Act of 1990, 1990). However, organizations including state legal aid agencies, such as the Illinois Legal Aid Organization, provide examples (Illinois Legal Aid Online, 2017). These include alcoholism, asthma, blindness, deafness, cancer, cerebral palsy, depression, heart disease, migraine headaches, and multiple sclerosis. Fibromyalgia is not included in this list. Thus, some individuals with fibromyalgia may not understand they are entitled to accommodations.

A Google search with the query: "is fibromyalgia considered a disability?" yields a web page providing information about social security benefits from a website called Disability Secrets (Laurence, 2018) as one of the first results. Upon visiting the website, two live chat opportunities pop up immediately, which guide the information seeker to consider legal help. An additional banner at the top of the screen prompts: "Online Now Connect with SSDI attorneys in your area." While directing individuals towards legal help can be helpful for those who seek disability benefits, this does not help those who seek information about staying at work, and are perhaps seeking to understand whether the diagnosis of fibromyalgia entitles them to work accommodations.

The International Journal of Information, Diversity, \& Inclusion, 3(3), 2019

ISSN 2574-3430, jps. library.utoronto.ca/index.php/ijidi/index

DOI: $10.33137 /$ ijidi.v3i3.32964 
Sample search keywords, search results, and underlying messages are presented in Table 1. Taken together, they demonstrate the importance of considering how information search practices and information balance in the returned search results and articles could potentially influence conceptual understanding of an issue, and the need for a better understanding of how individuals go about seeking information, the information that they encounter, and what they take away from those sources. Additionally, there is a need to better understand the extent to which individuals with fibromyalgia and/or other chronic pain-related conditions understand how to approach work-related issues.

Table 1. Information Searches about Fibromyalgia and Work: Examples and Implications

\begin{tabular}{|c|c|c|}
\hline Keywords & Sample Search Results & Message \\
\hline "fibromyalgia work" & $\begin{array}{l}\text { - Disability Benefits } \\
\text { Center: "Can I } \\
\text { continue working } \\
\text { with fibromyalgia?" } \\
\text { - WebMD: } \\
\text { "Fibromyalgia: Work } \\
\text { and Disability" } \\
\text { VeryWell Health: } \\
\text { "Can I keep working } \\
\text { with fibromyalgia or } \\
\text { ME/CFS" }\end{array}$ & $\begin{array}{l}\text { The search result titles } \\
\text { suggest an underlying } \\
\text { question that is being } \\
\text { answered. } \\
\text { The information balance of } \\
\text { the WebMD article and the } \\
\text { nature of the search results } \\
\text { steer the reader to leaving } \\
\text { the workforce and applying } \\
\text { for disability. }\end{array}$ \\
\hline $\begin{array}{l}\text { "fibromyalgia work } \\
\text { accommodations" }\end{array}$ & $\begin{array}{l}\text { Job Accommodation } \\
\text { Network: } \\
\text { "Fibromyalgia" }\end{array}$ & $\begin{array}{l}\text { The website provides a } \\
\text { variety of resources for } \\
\text { individuals seeking } \\
\text { information about work } \\
\text { accommodations, enabling } \\
\text { readers to take steps to } \\
\text { advocate for themselves. }\end{array}$ \\
\hline $\begin{array}{l}\text { "is fibromyalgia } \\
\text { considered a } \\
\text { disability?" }\end{array}$ & $\begin{array}{l}\text { Disability Secrets: } \\
\text { "Social security } \\
\text { disability (SSDI \& SSI) } \\
\text { for fibromyalgia" }\end{array}$ & $\begin{array}{l}\text { - The search results direct the } \\
\text { reader to apply for disability } \\
\text { benefits. }\end{array}$ \\
\hline
\end{tabular}

Information awareness and information-seeking skills can be invaluable in the search for information. Previous research in other health contexts has observed that a lack of awareness and knowledge can be an obstacle to successful health management (Chen, 2016; St. Jean, 2012). There can be differences in the level of awareness that people have of the existence of health information, their access to health information, their skills to find and understand it, and the manner in which they may go about seeking information (e.g., the sources that they use and how they formulate search queries). These differences can, in turn, lead to differences in the information found, the extent to which the information can be utilized, and inequities in successful management of chronic health conditions in the workplace. If useful information exists but is not easily found, or if information needs to be integrated across multiple sources and this is not being done, then individuals will still have trouble advocating for themselves and managing their work lives in other ways.

The International Journal of Information, Diversity, \& Inclusion, 3(3), 2019

ISSN 2574-3430, jps. library.utoronto.ca/index.php/ijidi/index

DOI: $10.33137 /$ ijidi.v3i3.32964 
It is imperative that library and information science professionals investigate information awareness and information seeking behaviors, as well as devise ways for dissemination of this information more broadly. Since the current literature suggests individuals may not seek out organizational guidance when they first start experiencing problems at work, it is important to ensure that information is publicly available, easily findable, and that lay health consumers are able to understand, interpret, and evaluate the health information they encounter. The National Library of Medicine offers guidance on how to evaluate online health information (U.S. National Library of Medicine, n.d.), encouraging consumers to consider factors such as the operator of the website, funding, quality, and privacy. Previous research concerning search behavior of people with fibromyalgia has reported that people may start out with less sophisticated search behaviors and learn to form more specific and targeted queries over time (Chen, 2016).

It can also be important to consider different ways for promoting the development of selfadvocacy skills and understanding, such as role playing, bibliotherapy, and art therapy. For example, Dali (2018) suggests that literature, cinematic works, games, and interactive electronic media and music might help people visualize how inclusive practices can be incorporated into campus work environments. As people learn and process information in different ways, providing options can facilitate effective interpretation and utilization of information.

\section{Considering Stakeholder Perspectives over Time}

To develop work environments and systems in which all individuals can be productive and satisfied, it is important to consider the perspectives of all stakeholders involved, including employees, employers, and service providers. With regard to employees, previous research has reported that they most valued flexible work opportunities, including flexible hours, job-sharing, the ability to work at home, part-time work, and a flexible leave policy (Crooks, 2007b; Schrader et al., 2014). Other factors, such as allocation of suitable accommodations, hiring and retention of individuals with disabilities, disability awareness training for employees, human resources personnel who are familiar with disability and accommodations, and a fair system for submitting grievances, can facilitate disclosure (Schrader et al., 2014).

Previous research has observed that vocational rehabilitation efforts have focused on the supply, but not the demand-side of the labor market, providing training and placement, with little regard for the real operational needs of employers (Luecking, 2008). It is important to consider the accommodations process not only in terms of its benefits for the employee, but also for the employer (MacDonald-Wilson et al., 2008). These could include direct benefits, such as retention of qualified employees, increased worker productivity, and avoiding the cost of training new employees. It could also include indirect benefits, such as improved interactions among employees, increased company morale, and increased overall company productivity (Solovieva, Dowler, \& Walls, 2011). Providing education to employers can also be helpful. Previous research has shown that knowledge of disability legislation is associated with greater willingness to help and belief that employees with disabilities could be productive (Telwatte, Anglim, Wynton, \& Moulding, 2017), and that employers' attitudes toward hiring individuals with disabilities tends to improve with exposure (Luecking, 2008).

There has been research comparing the perspectives of three different stakeholders in the accommodations process: employers, employees with disabilities, and rehabilitation service providers. There is often concordance in the perspectives of these different stakeholders. For example, in one study, the three types of stakeholders ranked the same five factors as most

The International Journal of Information, Diversity, \& Inclusion, 3(3), 2019

ISSN 2574-3430, jps.library.utoronto.ca/index.php/ijidi/index

DOI: $10.33137 /$ ijidi.v3i3.32964 
important: supportiveness of an employee's direct supervisor, the employer's support for requesting accommodations, communication between the employer and the employee, employer's understanding of disabilities, and ADA eligibility (Dong, Oire, MacDonald-Wilson, \& Fabian, 2013).

Though employers and employees generally agree that employees should present credible requests for accommodations, stakeholders can differ in terms of their expectations of one another (Gold et al., 2012). Employees argue that employers have a moral obligation to provide suitable environments for employees to work, whereas employers justify their reluctance to provide accommodations based on legal and financial reasons. Creating a climate of trust between employees and human resource management, line managers, colleagues, and work team members, has been proposed to enrich the work experiences of those with chronic illness (Vijayasingham, Jogulu, \& Allotey, 2016).

The literature on stakeholder perspectives highlights the importance of long-term stakeholder involvement and a collaborative process towards cultivation of work environments that promote work productivity and satisfaction for all. Many of the key emergent factors in the literature, such as communication, trust, and work climate, are not characteristics of an environment that can be established through a one-time effort, but rather through sustained efforts over time by all parties in accordance with disability-friendly policies and legislation.

Continued involvement of stakeholders in the development of a systemic, disability-friendly environment, as opposed to a system in which individuals apply for one-time or incremental accommodations, could potentially facilitate a more positive working environment for all. This would mean that individuals in the work environment each have a responsibility. Employees who may need accommodations have a responsibility to communicate with employers, supervisors, and co-workers in a timely fashion; to promote smooth interactions between all employees; and to avoid work delays and sacrificing work quality. Co-workers and supervisors have a responsibility to consider the needs of those requiring accommodations. All individuals have a responsibility to consider the overall work environment and work together to develop solutions. Additionally, it is important to acknowledge that anyone could both be accommodating of others and need accommodations themselves.

The existing literature on employer perspectives addresses the subject of hiring of individuals with disabilities in general, rather than fibromyalgia specifically. While we have reviewed this literature because it provides an overview of the overall climate that individuals with fibromyalgia might face as they approach the labor market, it is important to recognize that some aspects of the disability literature may apply, whereas others do not. For example, employers are more likely to hold positive attitudes towards individuals with physical disabilities rather than intellectual or psychiatric ones (Hernandez, Keys, \& Balcazar, 2000). Individuals with fibromyalgia often experience invalidating experiences in multiple spheres of life including work, where they may encounter disbelief from co-workers as well as supervisors (Crooks, 2007a; Oldfield et al., 2016). Thus, though there is literature in general suggesting that employers are amenable to hiring individuals with disabilities, there remains a need for more research on employers' attitudes in relation to conditions that may be associated with greater stigma, such as fibromyalgia. In addition, it is worth noting that we do not regard employers as a monolithic group. It is likely that employers of different types (e.g., human resources professionals, managers, small business owners) and sectors may hold different attitudes, and more research is needed to understand how their attitudes and approaches towards employing individuals with

The International Journal of Information, Diversity, \& Inclusion, 3(3), 2019

ISSN 2574-3430, jps.library.utoronto.ca/index.php/ijidi/index

DOI: $10.33137 /$ ijidi.v3i3.32964 
fibromyalgia might differ.

\section{Conclusion}

This paper makes the following main contributions. First, we reviewed extant literature concerning work experiences and work accommodations of individuals with fibromyalgia, situated it in the broader literature concerning the work experiences of disabilities, and identified a gap in conceptual models in terms of the role of information in facilitating workplace self-advocacy. Second, we identified gaps in the academic literature concerning the types of information resources that are available to those with fibromyalgia seeking information on accommodations, and in our knowledge of how individuals needing such information might search for and interpret that information, once found. Though we recognize that more extensive research is needed, we present examples of information that is available and some of the issues that may arise concerning how individuals search for and interpret information, and we present suggestions for wider dissemination of information about work accommodations. Third, we emphasize the need for involvement among all concerned stakeholders over time. A clearer understanding of how individuals with fibromyalgia might seek and encounter information about work and efforts to disseminate this information among stakeholders over time can result in a more equitable distribution of workplace benefits, and improved overall workplace productivity and satisfaction. This paper may be of interest to a wide audience, including researchers from multiple disciplines, health care providers who work with persons with chronic illnesses, practitioners who develop patient education resources and information interventions, and health policy researchers striving to achieve health equity at the community and population levels.

\section{References}

Al Dhanhani, A. M., Gignac, M. A. M., Beaton, D. E., Su, J., \& Fortin, P. R. (2015). Job accommodations availability and utilization among people with lupus: An examination of workplace activity limitations and work context factors: Availability and use of job accommodations among lupus patients. Arthritis Care \& Research, 67(11), 1536-1544. https://doi.org/10.1002/acr.22662

Allaire, S. H., Wei Li, \& LaValley, M. P. (2003). Work barriers experienced and job accommodations used by persons with arthritis and other rheumatic diseases. Rehabilitation Counseling Bulletin, 46(3), 147-156. https: //doi.org/10.1177/00343552030460030301

Americans with Disabilities Act of 1990, Pub. L. No. 101-336, § 104, 328 (1990).

Ashe, S. C., Furness, P. J., Taylor, S. J., Haywood-Small, S., \& Lawson, K. (2017). A qualitative exploration of the experiences of living with and being treated for fibromyalgia. Health Psychology Open, 4(2), 1-12. https://doi.org/10.1177/2055102917724336

Barker, K. (2005). The fibromyalgia story. Philadelphia, PA: Temple University Press. Retrieved from https: / / muse.jhu.edu/book/9573

Barker, K. K. (2008). Electronic support groups, patient-consumers, and medicalization: The

The International Journal of Information, Diversity, \& Inclusion, 3(3), 2019

ISSN 2574-3430, jps. library.utoronto.ca/index.php/ijidi/index

DOI: $10.33137 /$ ijidi.v3i3.32964 
case of contested illness. Journal of Health and Social Behavior, 49(1), 20-36. https://doi.org/10.1177/002214650804900103

Bellato, E., Marini, E., Castoldi, F., Barbasetti, N., Mattei, L., Bonasia, D. E., \& Blonna, D. (2012). Fibromyalgia syndrome: Etiology, pathogenesis, diagnosis, and treatment. Pain Research and Treatment, 2012, 1-17. https://doi.org/10.1155/2012/426130

Bossema, E. R., Kool, M. B., Cornet, D., Vermaas, P., de Jong, M., van Middendorp, H., \& Geenen, R. (2012). Characteristics of suitable work from the perspective of patients with fibromyalgia. Rheumatology, 51(2), 311-318. https://doi.org/10.1093/rheumatology/ker312

Bragazzi, N. L., Amital, H., Adawi, M., Brigo, F., Watad, S., Aljadeff, G., ... Watad, A. (2017). What do people search online concerning the "elusive" fibromyalgia? Insights from a qualitative and quantitative analysis of Google Trends. Clinical Rheumatology, 36(8), 1873-1878. https://doi.org/10.1007/s10067-017-3665-y

Briones-Vozmediano, E. (2016). The social construction of fibromyalgia as a health problem from the perspective of policies, professionals, and patients. Global Health Action, 9. https: / / doi.org/10.3402/gha.v9.31967

Burckhardt, C. S., Liedberg, G. M., Henriksson, C. M., \& Kendall, S. (2005). The impact of fibromyalgia on employment status of newly-diagnosed young women: A pilot study. Journal of Musculoskeletal Pain, 13(2), 31-41. https://doi.org/10.1300/J094v13n02_05

Chen, A. T. (2012). Exploring online support spaces: Using cluster analysis to examine breast cancer, diabetes and fibromyalgia support groups. Patient Education and Counseling, 87(2), 250-257. https://doi.org/10.1016/j.pec.2011.08.017

Chen, A. T. (2015). Meaning, Information and Online Participation along the Illness Journey: The Story for Fibromyalgia Patients (Doctoral dissertation). Retrieved from ProQuest Dissertations \& Theses Global. (3719731)

Chen, A. T. (2016). The relationship between health management and information behavior over time: A study of the illness journeys of people living with fibromyalgia. Journal of Medical Internet Research, 18(10), e269. https://doi.org/10.2196/jmir.5309

Clair, J. A., Beatty, J. E., \& Maclean, T. L. (2005). Out of sight but not out of mind: Managing invisible social identities in the workplace. Academy of Management Review, 30(1), 7895. https://doi.org/10.5465/amr.2005.15281431

Collado, A., Gomez, E., Coscolla, R., Sunyol, R., Solé, E., Rivera, J., ... Castells, X. (2014). Work, family and social environment in patients with Fibromyalgia in Spain: An epidemiological study: EPIFFAC study. BMC Health Services Research, 14(1), 513. https://doi.org/10.1186/s12913-014-0513-5

Cooper, S., \& Gilbert, L. (2017). The role of "social support" in the experience of fibromyalgia - Narratives from South Africa. Health \& Social Care in the Community, 25(3), 10211030. https://doi.org/10.1111/hsc.12403

The International Journal of Information, Diversity, \& Inclusion, 3(3), 2019

ISSN 2574-3430, jps. library.utoronto.ca/index.php/ijidi/index

DOI: $10.33137 /$ ijidi.v3i3.32964 
Crooks, V. A. (2007a). Exploring the altered daily geographies and lifeworlds of women living with fibromyalgia syndrome: A mixed-method approach. Social Science \& Medicine, 64(3), 577-588. https://doi.org/10.1016/j.socscimed.2006.09.025

Crooks, V. A. (2007b). Women's experiences of developing musculoskeletal diseases: Employment challenges and policy recommendations. Disability and Rehabilitation, 29(14), 1107-1116. https://doi.org/10.1080/09638280600948193

Dali, K. (2018). The lifeways we avoid: The role of information avoidance in discrimination against people with disabilities. Journal of Documentation, 74(6), 1258-1273. https://doi.org/10.1108/JD-04-2018-0057

Daraz, L., MacDermid, J. C., Wilkins, S., Gibson, J., \& Shaw, L. (2011). Information preferences of people living with fibromyalgia - a survey of their information needs and preferences. Rheumatology Reports, 3(1). https://doi.org/10.4081/rr.2011.e7

de Vries, H. J., Brouwer, S., Groothoff, J. W., Geertzen, J. H., \& Reneman, M. F. (2011). Staying at work with chronic nonspecific musculoskeletal pain: a qualitative study of workers' experiences. BMC Musculoskeletal Disorders, 12(1), 126.

https://doi.org/10.1186/1471-2474-12-126

Dellwo, A. (2017, November 8). Can I keep working with fibromyalgia or ME/CFS? Retrieved from https: / / www.verywellhealth.com/can-i-keep-working-with-fibromyalgia-and-cfs716193

Disability Benefits Center. (2019). Can I work with fibromyalgia? Retrieved from https://www.disabilitybenefitscenter.org/disability-work/fibromyalgia

Dong, S., Oire, S. N., MacDonald-Wilson, K. L., \& Fabian, E. S. (2013). A comparison of perceptions of factors in the job accommodation process among employees with disabilities, employers, and service providers. Rehabilitation Counseling Bulletin, 56(3), 182-189. https://doi.org/10.1177/0034355212468618

Dunstan, D. A., \& MacEachen, E. (2013). Bearing the brunt: Co-workers' experiences of work reintegration processes. Journal of Occupational Rehabilitation, 23(1), 44-54. https://doi.org/10.1007/s10926-012-9380-2

Dunstan, D. A., \& MacEachen, E. (2014). A theoretical model of co-worker responses to work reintegration processes. Journal of Occupational Rehabilitation, 24(2), 189-198. https://doi.org/10.1007/s10926-013-9461-x

Edwards, M., Wood, F., Davies, M., \& Edwards, A. (2012). The development of health literacy in patients with a long-term health condition: The health literacy pathway model. BMC Public Health, 12(1), 130. https://doi.org/10.1186/1471-2458-12-130

Emens, E. (2017). Disability and equality law. New York, NY: Routledge.

Franche, R.-L., Baril, R., Shaw, W., Nicholas, M., \& Loisel, P. (2005). Workplace-based returnto-work interventions: Optimizing the role of stakeholders in implementation and research. Journal of Occupational Rehabilitation, 15(4), 525-542.

The International Journal of Information, Diversity, \& Inclusion, 3(3), 2019

ISSN 2574-3430, jps.library.utoronto.ca/index.php/ijidi/index

DOI: $10.33137 /$ ijidi.v3i3.32964 
https://doi.org/10.1007/s10926-005-8032-1

Gignac, M. A. M., Cao, X., \& McAlpine, J. (2015). Availability, need for, and use of work accommodations and benefits: Are they related to employment outcomes in people with arthritis? Arthritis Care \& Research, 67(6), 855-864.

https: // doi.org/10.1002/acr.22508

Gignac, M. A. M., Cao, X., Lacaille, D., Anis, A. H., \& Badley, E. M. (2008). Arthritis-related work transitions: A prospective analysis of reported productivity losses, work changes, and leaving the labor force. Arthritis Care \& Research, 59(12), 1805-1813. https://doi.org/10.1002/art.24085

Glavare, M., Löfgren, M., \& Schult, M. -L. (2012). Between unemployment and employment: Experience of unemployed long-term pain sufferers. Work, 43(4), 475-485. https://doi.org/10.3233/WOR-2012-1394

Goering, S. (2015). Rethinking disability: The social model of disability and chronic disease. Current Reviews in Musculoskeletal Medicine, 8(2), 134-138. https: //doi.org/10.1007/s12178-015-9273-z

Gold, P. B., Oire, S. N., Fabian, E. S., \& Wewiorski, N. J. (2012). Negotiating reasonable workplace accommodations: Perspectives of employers, employees with disabilities, and rehabilitation service providers. Journal of Vocational Rehabilitation, 37(1), 25-37.

Greene, K. (2015). An integrated model of health disclosure decision-making. In T. Afifi \& W. Afifi (Eds.), Uncertainty, information management, and disclosure decisions: Theories and applications. New York, NY: Routledge.

Griffin, R. J., Powell, M., Dunwoody, S., Neuwirth, K., Clark, D., \& Novotny, V. (2004). Testing the robustness of a risk information processing model. Paper presented to the Communication Theory and Methodology Division, Association for Education in Journalism and Mass Communication at the Association for Education in Journalism and Mass Communication Annual Convention, Toronto, Canada. https://doi.org/10.13140/2.1.3856.0960

Guymer, E. K., Littlejohn, G. O., Brand, C. K., \& Kwiatek, R. A. (2016). Fibromyalgia onset has a high impact on work ability in Australians. Internal Medicine Journal, 46(9), 10691074. https://doi.org/10.1111/imj.13135

Henriksson, C., Liedberg, G., \& Gerdle, B. (2005). Women with fibromyalgia: Work and rehabilitation. Disability and Rehabilitation, 27(12), 685-694. https://doi.org/10.1080/09638280400009089

Hernandez, B., Keys, C., \& Balcazar, F. (2000). Employer attitudes towards workers with disabilities and their ADA employment rights: A literature review. Journal of Rehabilitation, 66(4), 4-16.

Hubertsson, J., Petersson, I. F., Arvidsson, B., \& Thorstensson, C. A. (2011). Sickness absence in musculoskeletal disorders - patients' experiences of interactions with the Social Insurance Agency and health care. A qualitative study. BMC Public Health, 11(1), 107.

The International Journal of Information, Diversity, \& Inclusion, 3(3), 2019

ISSN 2574-3430, jps.library.utoronto.ca/index.php/ijidi/index

DOI: $10.33137 /$ ijidi.v3i3.32964 
https://doi.org/10.1186/1471-2458-11-107

Illinois Legal Aid Online (2017, January). Disabilities recognized under the ADA. Retrieved from https://www.illinoislegalaid.org/legal-information/disabilities-recognized-under-ada

Jans, L. H., Kaye, H. S., \& Jones, E. C. (2012). Getting hired: Successfully employed people with disabilities offer advice on disclosure, interviewing, and job search. Journal of Occupational Rehabilitation, 22(2), 155-165. https://doi.org/10.1007/s10926-0119336-y

Job Accommodation Network. (n.d.). Fibromyalgia. Retrieved from https://askjan.org/disabilities/Fibromyalgia.cfm

Johnson, J. D., \& Meischke, H. (1993). A comprehensive model of cancer-related information seeking applied to magazines. Human Communication Research, 19(3), 343-367.

Juuso, P., Skär, L., Sundin, K., \& Söderberg, S. (2016). The workplace experiences of women with fibromyalgia: Fibromyalgia in working women. Musculoskeletal Care, 14(2), 69-76. https://doi.org/10.1002/msc.1125

Kirk-Brown, A., \& van Dijk, P. (2014). An empowerment model of workplace support following disclosure, for people with MS. Multiple Sclerosis Journal, 20(12), 1624-1632. https://doi.org/10.1177/1352458514525869

Laurence, B. K. (2018). Social Security Disability (SSDI \& SSI) for fibromyalgia. Retrieved from https: / /www.disabilitysecrets.com/resources/social-security-disability-ssdi-ssifibromyalgia.htm

Lee, L. K., Ebata, N., Hlavacek, P., DiBonaventura, M., Cappelleri, J. C., \& Sadosky, A. (2016). Humanistic and economic burden of fibromyalgia in Japan. Journal of Pain Research, 9, 967-978. https: //doi.org/10.2147/JPR.S110707

Leslie, M., Kinyanjui, B., Bishop, M., Rumrill, P. D., \& Roessler, R. T. (2015). Patterns in workplace accommodations for people with multiple sclerosis to overcome cognitive and other disease-related limitations. NeuroRehabilitation, 37(3), 425-436. https://doi.org/10.3233/NRE-151271

Liedberg, G. M. , \& Henriksson, C. M. (2002). Factors of importance for work disability in women with fibromyalgia: An interview study. Arthritis Care \& Research, 47(3), 266274. https://doi.org/10.1002/art.10454

Löfgren, M., Ekholm, J., \& Öhman, A. (2006). 'A constant struggle': Successful strategies of women in work despite fibromyalgia. Disability and Rehabilitation, 28(7), 447-455. https://doi.org/10.1080/09638280500197891

Löfgren, M., Schult, M.-L., Öhman, A., Julin, P., \& Ekholm, J. (2016). Fibromyalgia Syndrome or Chronic Fatigue Syndrome/Myalgic Encephalomyelitis and Factors Influencing Work Disability in Women. In Handbook of Return to Work (pp. 459-480). Boston, MA: Springer. https://doi.org/10.1007/978-1-4899-7627-7_26

The International Journal of Information, Diversity, \& Inclusion, 3(3), 2019

ISSN 2574-3430, jps.library.utoronto.ca/index.php/ijidi/index

DOI: $10.33137 /$ ijidi.v3i3.32964 
Luecking, R. G. (2008). Emerging employer views of people with disabilities and the future of job development. Journal of Vocational Rehabilitation, 29, 3-13.

MacDonald-Wilson, K. L., Fabian, E. S., \& Dong, S. (2008). Best practices in developing reasonable accommodations in the workplace: Findings based on the research literature. The Rehabilitation Professional, 16(4), 221-232.

Mancuso, C. A., Paget, S. A., \& Charlson, M. E. (2000). Adaptations made by rheumatoid arthritis patients to continue working: A pilot study of workplace challenges and successful adaptations. Arthritis \& Rheumatism, 13(2), 89-99. https: // doi.org/10.1002/1529-0131(200004)13:2<89::AID-ANR3>3.0.CO;2-L

Mannerkorpi, K., \& Gard, G. (2012). Hinders for continued work among persons with fibromyalgia. BMC Musculoskeletal Disorders, 13(1), 96. https://doi.org/10.1186/1471. 2474-13-96

Meade, M., Rumrill, P., Krause, J. S., Reed, K. S., \& Aust, R. (2016). Perceptions of quality of employment outcomes after multiple sclerosis: A qualitative study. Journal of Rehabilitation, 82(2), 31-40.

Munir, F., Leka, S., \& Griffiths, A. (2005). Dealing with self-management of chronic illness at work: Predictors for self-disclosure. Social Science \& Medicine, 60(6), 1397-1407. https://doi.org/10.1016/j.socscimed.2004.07.012

Nevala, N., Pehkonen, I., Koskela, I., Ruusuvuori, J., \& Anttila, H. (2015). Workplace accommodation among persons with disabilities: A systematic review of its effectiveness and barriers or facilitators. Journal of Occupational Rehabilitation, 25(2), 432-448. https://doi.org/10.1007/s10926-014-9548-z

Oldfield, M. (2014). Portrayals of fibromyalgia and paid work: Too sick to work? In S.-D. Stone, V. A. Crooks, \& M. Owen (Eds.), Working bodies: Chronic illness in the Canadian workplace (pp. 31-50). Montreal, Canada: McGill-Queen's University Press.

Oldfield, M., MacEachen, E., Kirsh, B., \& MacNeill, M. (2016). Impromptu everyday disclosure dances: How women with fibromyalgia respond to disclosure risks at work. Disability and Rehabilitation, 38(15), 1442-1453. https://doi.org/10.3109/09638288.2015.1103794

Oldfield, M., MacEachen, E., Kirsh, B., \& MacNeill, M. (2017). Helping employees with fibromyalgia manage their reputations through disclosure dances. Ontario Occupational Health Nurses Association (OOHNA) Journal, 36(1), 28-33.

Oldfield, M., MacEachen, E., MacNeill, M., \& Kirsh, B. (2018). 'You want to show you're a valuable employee': A critical discourse analysis of multi-perspective portrayals of employed women with fibromyalgia. Chronic Illness, 14(2), 135-153.

https://doi.org/10.1177/1742395317714034

Oliver, M. (1996). Defining impairment and disability: Issues at stake. In C. Barnes \& G. Mercer (Eds.), Exploring the divide: Illness and disability (pp. 29-54). Leeds, UK: The Disability Press.

The International Journal of Information, Diversity, \& Inclusion, 3(3), 2019

ISSN 2574-3430, jps.library.utoronto.ca/index.php/ijidi/index

DOI: $10.33137 /$ ijidi.v3i3.32964 
Padkapayeva, K., Posen, A., Yazdani, A., Buettgen, A., Mahood, Q., \& Tompa, E. (2017). Workplace accommodations for persons with physical disabilities: Evidence synthesis of the peer-reviewed literature. Disability and Rehabilitation, 39(21), 2134-2147. https://doi.org/10.1080/09638288.2016.1224276

Palmer, K. T., Harris, E. C., Linaker, C., Barker, M., Lawrence, W., Cooper, C., \& Coggon, D. (2012). Effectiveness of community- and workplace-based interventions to manage musculoskeletal-related sickness absence and job loss: A systematic review. Rheumatology, 51(2), 230-242. https://doi.org/10.1093/rheumatology/ker086

Palstam, A., Gard, G., \& Mannerkorpi, K. (2013). Factors promoting sustainable work in women with fibromyalgia. Disability and Rehabilitation, 35(19), 1622-1629. https://doi.org/10.3109/09638288.2012.748842

Purc-Stephenson, R. J., Dostie, J., \& Smith, H. J. (2018). Swimming against the current: A qualitative review of the work experiences and adaptations made by employees with arthritis. Arthritis Care \& Research, 70(11), 1587-1597. https://doi.org/10.1002/acr.23528

Rumrill, P. D., Roessler, R. T., Bishop, M. L., Li, J., Hendricks, D. J., \& Leslie, M. (2016). Women with multiple sclerosis and the importance and satisfaction they ascribe to selected employment concerns: Results from a national survey, Journal of Rehabilitation, 82(2), 51-58.

Sallinen, M., Kukkurainen, M. L., Peltokallio, L., \& Mikkelsson, M. (2010). Women's narratives on experiences of work ability and functioning in fibromyalgia. Musculoskeletal Care, 8(1), 18-26. https://doi.org/10.1002/msc.162

Santuzzi, A. M., \& Waltz, P. R. (2016). Disability in the workplace: A unique and variable identity. Journal of Management, 42(5), 1111-1135. https://doi.org/10.1177/0149206315626269

Santuzzi, A. M., Waltz, P. R., Finkelstein, L. M., \& Rupp, D. E. (2014). Invisible disabilities: Unique challenges for employees and organizations. Industrial and Organizational Psychology, 7(02), 204-219. https://doi.org/10.1111/iops.12134

Schrader, S. von, Malzer, V., \& Bruyère, S. (2014). Perspectives on disability disclosure: The importance of employer practices and workplace climate. Employee Responsibilities and Rights Journal, 26(4), 237-255. https://doi.org/10.1007/s10672-013-9227-9

Simmons, R. D., Tribe, K. L., \& McDonald, E. A. (2010). Living with multiple sclerosis: Longitudinal changes in employment and the importance of symptom management. Journal of Neurology, 257(6), 926-936. https://doi.org/10.1007/s00415-009-5441-7

Söderberg, S., \& Lundman, B. (2001). Transitions experienced by women with fibromyalgia. Health Care for Women International, 22(7), 617-631. https://doi.org/10.1080/07399330127169

Söderberg, S., Strand, M., Haapala, M., \& Lundman, B. (2003). Living with a woman with fibromyalgia from the perspective of the husband. Journal of Advanced Nursing, 42(2),

The International Journal of Information, Diversity, \& Inclusion, 3(3), 2019

ISSN 2574-3430, jps.library.utoronto.ca/index.php/ijidi/index

DOI: $10.33137 /$ ijidi.v3i3.32964 
143-150. https://doi.org/10.1046/j.1365-2648.2003.02597.x

Solovieva, T. I., Dowler, D. L., \& Walls, R. T. (2011). Employer benefits from making workplace accommodations. Disability and Health Journal, 4(1), 39-45. https://doi.org/10.1016/j.dhjo.2010.03.001

St. Jean, B. (2012). I just don't know what I don't know!": A longitudinal investigation of the perceived usefulness of information to people with type 2 diabetes. Proceedings of the American Society for Information Science and Technology, 49(1), 1-10. https://doi.org/10.1002/meet.14504901030

Sundar, V., O’Neill, J., Houtenville, A. J., Phillips, K. G., Keirns, T., Smith, A., \& Katz, E. E. (2018). Striving to work and overcoming barriers: Employment strategies and successes of people with disabilities. Journal of Vocational Rehabilitation, 48(1), 93-109. https://doi.org/10.3233/JVR-170918

Telwatte, A., Anglim, J., Wynton, S. K. A., \& Moulding, R. (2017). Workplace accommodations for employees with disabilities: A multilevel model of employer decision-making. Rehabilitation Psychology, 62(1), 7-19. https://doi.org/10.1037/rep0000120

Toye, F., Seers, K., Allcock, N., Briggs, M., Carr, E., \& Barker, K. (2016). A synthesis of qualitative research exploring the barriers to staying in work with chronic musculoskeletal pain. Disability and Rehabilitation, 38(6), 566-572. https://doi.org/10.3109/09638288.2015.1049377

U.S. National Library of Medicine. (n.d.). Evaluating Internet Health Information: A Tutorial from the National Library of Medicine. Retrieved from https: //medlineplus.gov/webeval/webeval.html

Varekamp, I., \& van Dijk, F. J. H. (2010). Workplace problems and solutions for employees with chronic diseases. Occupational Medicine, 60(4), 287-293. https://doi.org/10.1093/occmed/kqq078

Varekamp, I., Verbeek, J. H., \& van Dijk, F. J. H. (2006). How can we help employees with chronic diseases to stay at work? A review of interventions aimed at job retention and based on an empowerment perspective. International Archives of Occupational and Environmental Health, 80(2), 87-97. https://doi.org/10.1007/s00420-006-0112-9

Vijayasingham, L., Jogulu, U., \& Allotey, P. (2016). Enriching the organizational context of chronic illness experience through an ethics of care perspective. Journal of Business Ethics, 153(1), 29-40. https://doi.org/10.1007/s10551-016-3362-9

Walitt, B., Nahin, R. L., Katz, R. S., Bergman, M. J., \& Wolfe, F. (2015). The prevalence and characteristics of fibromyalgia in the 2012 National Health Interview Survey. PLOS ONE, 10(9), e0138024. https://doi.org/10.1371/journal.pone.0138024

WebMD. (2018). Fibromyalgia: Work and disability. Retrieved from https://www.webmd.com/fibromyalgia/guide/fibromyalgia-work-and-disability\#1

Whei-Mei, S., Lee-Ing, T., Hsiu-Chin, H., \& Pin-Ru, H. (2018). The lived experiences of

The International Journal of Information, Diversity, \& Inclusion, 3(3), 2019

ISSN 2574-3430, jps.library.utoronto.ca/index.php/ijidi/index

DOI: $10.33137 /$ ijidi.v3i3.32964 
fibromyalgia in Taiwanese women. European Scientific Journal, 14(18), 49-64.

https://doi.org/10.19044/esj.2018.v14n18p49

White, K. P., Speechley, M., Harth, M., \& Ostbye, T. (1999). Comparing self-reported function and work disability in 100 community cases of fibromyalgia syndrome versus controls in London, Ontario: The London Fibromyalgia Epidemiology Study. Arthritis \& Rheumatism, 42(1), 76-83. https://doi.org/10.1002/1529-0131(199901)42:1<76::AIDANR10>3.0.CO;2-G

Williams-Whitt, K., Bültmann, U., Amick, B., Munir, F., Tveito, T. H., Anema, J. R., and the Hopkinton Conference Working Group on Workplace Disability Prevention. (2016). Workplace interventions to prevent disability from both the scientific and practice perspectives: A comparison of scientific literature, grey literature and stakeholder observations. Journal of Occupational Rehabilitation, 26(4), 417-433. https://doi.org/10.1007/s10926-016-9664-z

Wolfe, F., Brähler, E., Hinz, A., \& Häuser, W. (2013). Fibromyalgia prevalence, somatic symptom reporting, and the dimensionality of polysymptomatic distress: Results from a survey of the general population. Arthritis Care \& Research, 65(5), 777-785. https://doi.org/10.1002/acr.21931

Yang, Z. J., Aloe, A. M., \& Feeley, T. H. (2014). Risk Information Seeking and Processing Model: A Meta-Analysis. Journal of Communication, 64(1), 20-41. https://doi.org/10.1111/jcom.12071

Annie T. Chen (atchen@uw.edu) is an assistant professor in the Department of Biomedical Informatics and Medical Education at the University of Washington School of Medicine. Her main areas of research interest include information behaviors in the context of chronic illness, information sharing in online communities and other digital spaces, and the role that information may play in affording patient voice and participation. Particularly relevant to this article is her interest in the ways in which the information that we seek and encounter may shape our representations of health and wellbeing, and in turn affect our health management behaviors. Additionally, she employs a variety of different methods including qualitative research methods and text mining and visualization techniques, to better understand human behavior.

Holly Carpenter (holly.carpenter@asu.edu) is a higher education administrator and scholarpractitioner. She received her PhD in Educational Leadership and Policy Studies from Arizona State University. Her research interests focus on how faculty, staff, and students navigate higher education policies and procedures and best practices in higher education. One area of interest has been how faculty, staff, and students navigate the accommodations process at higher education institutions.

Mary Grace Flaherty (mgflaher@email.unc.edu) is an assistant professor at the School of Information and Library Science at the University of North Carolina at Chapel Hill. She received her PhD in Information Science \& Technology from Syracuse University where she was an IMLS Fellow. Dr. Flaherty has master's degrees from the University of Maryland and Johns Hopkins

The International Journal of Information, Diversity, \& Inclusion, 3(3), 2019

ISSN 2574-3430, jps. library.utoronto.ca/index.php/ijidi/index

DOI: $10.33137 /$ ijidi.v3i3.32964 
University. Her research interests are centered on health information seeking in medical contexts, and in the library setting. Her recent book, Promoting Individual and Community Health at the Library, is used by public librarians to guide health information provision and health promotion programs nationwide.

The International Journal of Information, Diversity, \& Inclusion, 3(3), 2019

ISSN 2574-3430, jps. library.utoronto.ca/index.php/ijidi/index

DOI: $10.33137 /$ ijidi.v3i3.32964 